\title{
Deep brain stimulation for aggressiveness: long-term follow-up and tractography study of the stimulated brain areas
}

\author{
Cristina V. Torres, PhD, ${ }^{1}$ Guillermo Blasco, MD, ${ }^{1}$ Marta Navas García, MD, ${ }^{1}$ \\ Elena Ezquiaga, PhD, ${ }^{5}$ Jesús Pastor, PhD, ${ }^{3}$ Lorena Vega-Zelaya, PhD, ${ }^{3}$ \\ Paloma Pulido Rivas, PhD, ${ }^{1}$ Silvia Pérez Rodrigo, MD, ${ }^{4}$ and Rafael Manzanares, MD ${ }^{2}$

\begin{abstract}
Departments of ${ }^{1}$ Neurosurgery, ${ }^{2}$ Neuroradiology, and ${ }^{3}$ Clinical Neurophysiology, University Hospital La Princesa, Madrid; ${ }^{4}$ Department of Neuroradiology, Clínica Anderson, Madrid; and ${ }^{5}$ Department of Psychiatry, University Hospital La Princesa,
\end{abstract} \\ Madrid, Spain
}

\begin{abstract}
OBJECTIVE Initial studies applying deep brain stimulation (DBS) of the posteromedial hypothalamus (PMH) to patients with pathological aggressiveness have yielded encouraging results. However, the anatomical structures involved in its therapeutic effect have not been precisely identified. The authors' objective was to describe the long-term outcome in their 7-patient series, and the tractography analysis of the volumes of tissue activated in 2 of the responders.

METHODS This was a retrospective study of 7 subjects with pathological aggressiveness. The findings on MRI with diffusion tensor imaging (DTI) in 2 of the responders were analyzed. The authors generated volumes of tissue activated according to the parameters used, and selected those volumes as regions of interest to delineate the tracts affected by stimulation.
\end{abstract}

RESULTS The series consisted of 5 men and 2 women. Of the 7 patients, 5 significantly improved with stimulation. The $\mathrm{PMH}$, ventral tegmental area, dorsal longitudinal fasciculus, and medial forebrain bundle seem to be involved in the stimulation field.

CONCLUSIONS In this series, 5 of 7 medication-resistant patients with severe aggressiveness who were treated with bilateral PMH DBS showed a significant long-lasting improvement. The PMH, ventral tegmental area, dorsal longitudinal fasciculus, and medial forebrain bundle seem to be in the stimulation field and might be responsible for the therapeutic effect of DBS.

https://thejns.org/doi/abs/10.3171/2019.11.JNS192608

KEYWORDS deep brain stimulation; diffusion tensor imaging; DTI; aggressiveness; functional connectivity; neuronal networks; neuromodulation; functional neurosurgery

$\mathrm{P}$ ATHOLOGICAL aggressiveness constitutes a significant social problem; it is estimated that it affects up to $45 \%$ of patients with mental retardation. ${ }^{31}$ Despite the fact that most cases are correctly managed with psychiatric medication, there is a subgroup that is resistant to conservative measures. ${ }^{41}$ Patients in this medicationresistant group frequently need to be admitted to institutions and managed under continuous mechanical restraint, which significantly impairs their quality of life and life expectancy. ${ }^{18,23,31,41}$
Long-term deep brain stimulation (DBS) of the posteromedial hypothalamus (PMH) has been shown to be an effective and safe therapy for patients with medication-resistant pathological aggressiveness. . $^{11,16,18,19,23,31,41}$ However, studies focusing on this treatment are very scarce, and the anatomical structures that are responsible for its therapeutic effect have not been precisely characterized..$^{39}$ Initially the PMH was selected as the DBS target based on previous successful results in series of PMH lesioning. ${ }^{13,21,30,33,34,36,37}$ The pioneer of this technique was Dr. Sano, a professor at

ABBREVIATIONS DBS = deep brain stimulation; DLF = dorsal longitudinal fasciculus; DTI = diffusion tensor imaging; $E E G=$ electroencephalography; FOV = field of view; $\mathrm{ICAP}=$ Inventory for Client and Agency Planning; MCP = midcommissural point; MFB = medial forebrain bundle; $\mathrm{OCD}=$ obsessive-compulsive disorder; $\mathrm{PMH}=$ posteromedial hypothalamus; VEEG = video EEG; VTa = ventral tegmental area.

SUBMITTED September 21, 2019. ACCEPTED November 26, 2019.

INCLUDE WHEN CITING Published online February 7, 2020; DOI: 10.3171/2019.11.JNS192608. 
the University of Tokyo, who selected the PMH because many experiments had demonstrated that lesioning or stimulating this region induced modifications in the aggressive response of experimental animals. ${ }^{34}$ Among other areas that seem to be part of the circuitry that controls aggressiveness, such as the uncus, amygdala, subgenual cingulate, and the dorsomedial thalamic nucleus, lesioning of the PMH seems to yield the most satisfactory results. $2,5,17,27,30,42$

Dr. Sano performed the lesions in an area that he named the "ergotropic triangle," which was situated 1-5 $\mathrm{mm}$ from the midline, $4 \mathrm{~mm}$ below and $2 \mathrm{~mm}$ posterior to the midpoint of the intercommissural line. ${ }^{41}$ This triangle occupied an area formed by the midcommissural point (MCP), the anterior edge of the mammillary bodies, and the superior part of the aqueduct. When stimulation was applied to this region, sympathetic responses and a desynchronization of electroencephalographic activity were elicited. Later, other groups replicated his results, and lesions in the PMH were performed in large series of patients. ${ }^{34}$

To our knowledge, 4 groups have reported series of patients with pathological aggressiveness who have benefited from DBS of the PMH, along with some other teams that have reported isolated cases. The area of stimulation is supposed to be the same as that traditionally referred to as the lesioning area, although there seem to be some differences between the target used by the different groups. . $^{18,23,31,40}$ Neurophysiological criteria and final stimulation parameters differed among groups, which also suggests lack of homogeneity in the final targets..$^{31,32}$ The mechanism of action of DBS for severe aggressiveness and how it affects brain networks remains unknown. ${ }^{40}$

The goal of this study was to report the long-term follow-up of our group's initial series, with an additional case, and to investigate the connectivity of the volumes of tissue activated generated from the active contacts in responders. With that purpose in mind, we performed tractography in which those volumes were selected as regions of interest, and we used a deterministic approach in diffusion tensor imaging (DTI).

\section{Methods}

This study was approved by our local clinical research ethics committee.

\section{Patients}

We reviewed the medical records of 7 patients with refractory pathological aggressiveness who had undergone PMH DBS at our institution since 2005. All of them had been diagnosed with severe medication-resistant aggressiveness of at least 5 years' duration by at least 2 different psychiatrists, and all had been treated with at least 5 psychotropic medications at correct doses and duration. Their quality of life was severely impaired, as assessed by the DSM-IV ${ }^{26}$ Global Assessment of Functioning ${ }^{15}$ scale (scores < 21), and their aggressiveness was classified as very serious according to the Maladaptive Behavior Index of the Spanish version of the Inventory for Client and Agency Planning $(\mathrm{ICAP})^{43}$ (score $\left.<-40\right)$. Epilepsy was confirmed in 3 patients by using videoelectroencephalography (VEEG), according to the International 10-20 system.

The decision to treat each patient with DBS was determined in a clinical session by a multidisciplinary team including neurosurgery, neurology, psychiatry, neurophysiology, radiology, and neuropsychology. The local ethics committee also discussed each case and approved the surgical treatment, based on chronicity, severity of the condition, and refractoriness to conservative measures. Informed consent was obtained in all cases from family and caregivers.

Five of the 7 patients (cases 1, 2, 3, 5, and 6) had been diagnosed with infantile autism and developmental delay (cases 3 and 5 had perinatal hypoxia and complicated births); their aggressiveness was associated with hyperkinesis, and their MRI results were normal. According to previous medical reports the patient in case 1 had undergone 4 radiofrequency lesions of the anterior cingulum, bilateral left stria terminalis, dorsomedial and intralaminar thalamic nuclei, internal capsule, and right $\mathrm{PMH}$, with temporary improvement of his symptoms. However, despite the fact that the rest of the lesions were visible, no lesions in the hypothalamic area were demonstrable in the patient's MRI. Two patients had hyperphagia and in 1 case, binge drinking.

The disease onset in the patient in case 4 was at 14 years of age, when he started developing obsessive-compulsive disorder (OCD), complex partial seizures, and aggressiveness. At the age of 18 years he underwent an operation for the resection of a temporal lobe hematoma and arteriovenous malformation, which worsened his symptoms; he developed severe heteroaggressiveness, disinhibition, bradypsychia, and binge eating. He was diagnosed with organic mental disorder and OCD.

The seventh patient had a normal development until he was 14 years old, when he had his first psychotic episode, with predominance of catatoniform symptoms with rigidity, negativism, and verbal and motor stereotypies in the form of aggressiveness, alternating with episodes of affective exaltation, disinhibition, aggression, and insomnia. He was diagnosed with schizophrenia. At the age of 21 years he had progressively worsened and was interned in a psychiatric institution. He underwent 7 electroconvulsive therapy sessions, with initial improvement and early relapse. When he was referred to our department at the age of 50 years, he needed to be under mechanical restraint for 24 hours a day (Table 1).

\section{Surgical Procedure}

The surgery we used has been previously described. ${ }^{41}$ In 4 cases, the surgical procedure was performed unilaterally in 2 stages; for the remaining 3 cases, it was performed bilaterally in 1 stage. Briefly, the stereotactic frame (Leksell model G; Elekta Instruments) was mounted and patients underwent a CT scan under general anesthesia. Planning was performed in the BrainLAB neuronavigation station, considering the tentative coordinates for the PMH as follows: $x=2 \mathrm{~mm}$ lateral to the wall of the third ventricle, and $y=0$ and $z=-2$ with respect to the MCP. We used the Leadpoint microelectrode recording system 


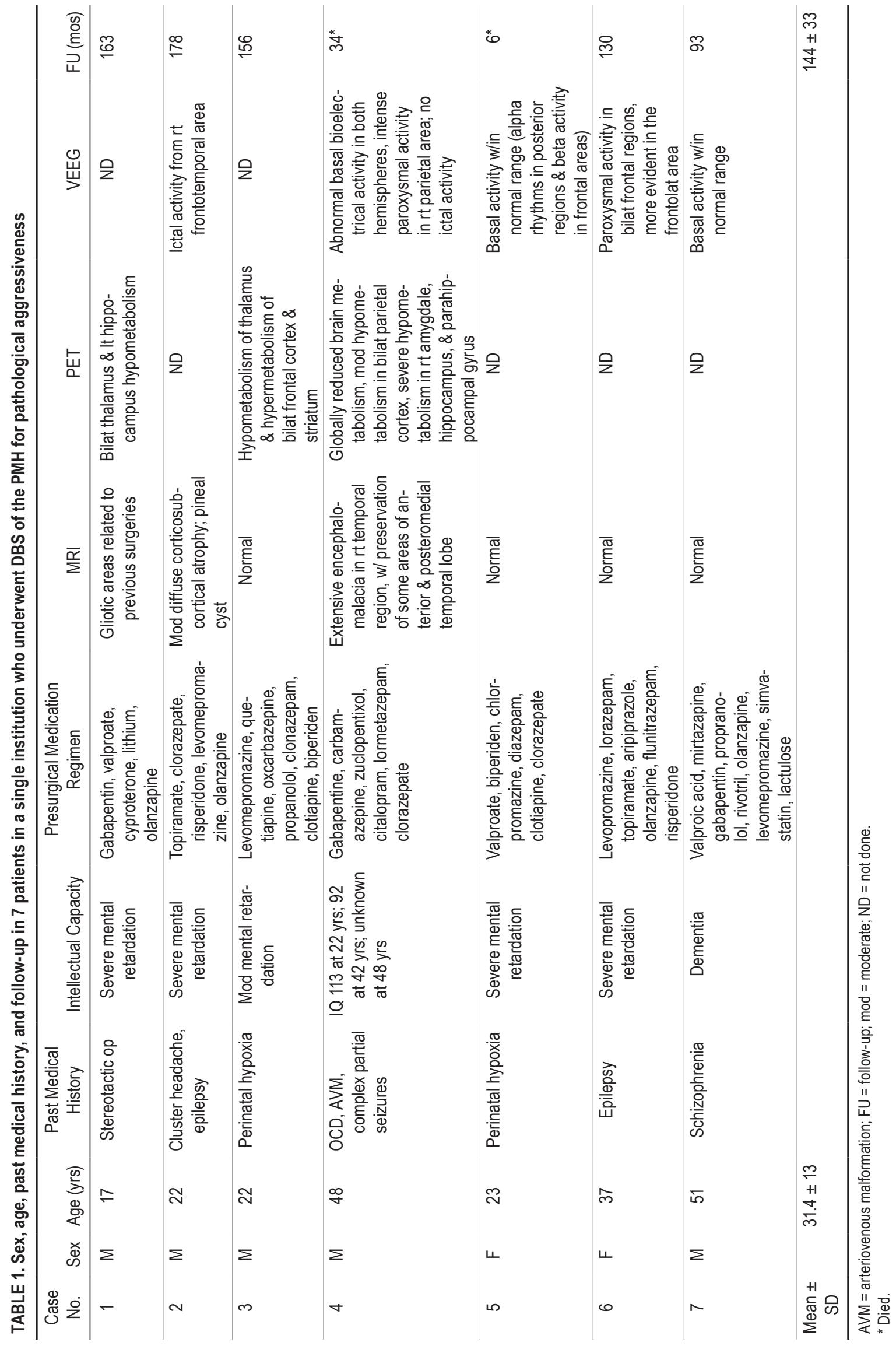


TABLE 2. Stimulation parameters used to generate the volumes of tissue activated in a series of patients treated with DBS of the PMH

\begin{tabular}{|c|c|c|c|c|c|c|}
\hline Case No. & Intensity & Duration & Frequency & Contacts & $A C-P C$ & Act Vol \\
\hline \multicolumn{7}{|l|}{1} \\
\hline Rt & $1.7 \mathrm{~mA}$ & $240 \mathrm{msec}$ & $130 \mathrm{~Hz}$ & $\mathrm{C}+, 0^{-}$ & $\begin{array}{l}x: 2 \mathrm{~mm} \\
\mathrm{y}:-4 \mathrm{~mm} \\
\mathrm{z}:-6.3 \mathrm{~mm}\end{array}$ & $\begin{array}{r}66.9 \mathrm{~mm}^{3} \\
122.9 \mathrm{~mm}^{3} \\
187.2 \mathrm{~mm}^{3}\end{array}$ \\
\hline $\mathrm{Lt}$ & $1.7 \mathrm{~mA}$ & $240 \mathrm{msec}$ & $100 \mathrm{~Hz}$ & $\mathrm{C}+, 1-$ & $\begin{array}{l}x: 3 m m \\
y:-1 m m \\
z:-1.2 m m\end{array}$ & $\begin{array}{r}70.1 \mathrm{~mm}^{3} \\
128.0 \mathrm{~mm}^{3} \\
193.9 \mathrm{~mm}^{3}\end{array}$ \\
\hline \multicolumn{7}{|l|}{2} \\
\hline $\mathrm{Rt}$ & $2.5 \mathrm{~mA}$ & $60 \mathrm{msec}$ & $185 \mathrm{~Hz}$ & $5+, 7-$ & $\begin{array}{l}\mathrm{x}: 2 \mathrm{~mm} \\
\mathrm{y}:-3 \mathrm{~mm} \\
\mathrm{z}:-4.3 \mathrm{~mm}\end{array}$ & $\begin{array}{c}11.0 \mathrm{~mm}^{3} \\
17.4 \mathrm{~mm}^{3} \\
22.7 \mathrm{~mm}^{3}\end{array}$ \\
\hline $\mathrm{Lt}$ & $2.5 \mathrm{~mA}$ & $60 \mathrm{msec}$ & $185 \mathrm{~Hz}$ & $2+, 3-$ & $\begin{array}{l}\mathrm{x}: 1.5 \mathrm{~mm} \\
\mathrm{y}:-3 \mathrm{~mm} \\
\mathrm{z}:-4 \mathrm{~mm}\end{array}$ & $\begin{array}{c}11.1 \mathrm{~mm}^{3} \\
14.0 \mathrm{~mm}^{3} \\
22.0 \mathrm{~mm}^{3}\end{array}$ \\
\hline
\end{tabular}

$\mathrm{AC}-\mathrm{PC}=$ anterior commissure-posterior commissure; Act $\mathrm{Vol}=$ activated volume.

(Medtronic) and 3 FHC (Frameless Hardware Co.) semimicroelectrodes (impedances 0.9-2.1 × $106 \mathrm{~W}$, separated by $2 \mathrm{~mm}$ ) to map the target, and patients were continuously monitored with electrocardiography, electromyography of cervical muscles (using 2 monopolar needle electrodes), and EEG with electrodes placed in Fp1/Fp2, T3/ T4, and $\mathrm{O} 1 / \mathrm{O} 2$; International 10-20 system). Six-second trains of electrical stimulation at $60 \mathrm{~Hz}, 60 \mathrm{msec}$, and $3 \mathrm{~mA}$ were applied using the reference contact of the microelectrode as a cathode and the insertion cannula as an anode. We decided to insert the definitive DBS leads (model 3389 [Medtronic] and Libra [St. Jude Medical]) in the position where the microrecording showed neuronal activity consistent with a nucleus, and where an increase in the heart rate of at least 5 beats, generalized theta-wave activity in the scalp EEG sequence, and an ipsilateral eye deviation were elicited with stimulation. The leads were connected to the pulse generators (Kinetra [Medtronic] and Libra PC [Abbott]), which were implanted in a subfascial pocket in the pectoral area.

\section{Postoperative Management}

Postoperative MRI sequences were carried out to confirm the position of the leads and to rule out any complications, and programming started during the first postoperative days, to monitor the patient's response in the VEEG room. The main outcome measures were the ICAP subscales. Patients underwent laboratory tests-including hormone profiles - preoperatively and every 3 months for the first 2 years after the surgery, and yearly thereafter. In the last 2 years, 3 of the patients underwent MRI with DTI in order to optimize their stimulation parameters, although only 2 of the MRI sequences were suitable for analysis because some artifacts related to movement appeared in the third case.

\section{DTI Acquisition}

The MRI data with DTI were acquired on a 1.5-T MR
General Electric scanner, using a single-shot echo planar imaging pulse sequence. The parameters were the following: TR 11,000 msec, field of view (FOV) $280 \times 280 \mathrm{~mm}$, matrix $128 \times 128$, section thickness $3 \mathrm{~mm}, 25$ gradient directions, and a b value of 1000 seconds $/ \mathrm{mm}^{2}$. An additional volume was acquired without diffusion weighting $\left(b=0\right.$ seconds $\left./ \mathrm{mm}^{2}\right)$, and the acquisition time was 8 minutes. These data were reconstructed to $1.1 \times 1.1 \times 2.9$ $\mathrm{mm}^{3}$ voxels. A T1-weighted sequence was acquired using a 3D magnetization-prepared rapid acquisition gradient echo, resulting in isotropic voxels of $1 \times 1 \times 1 \mathrm{~mm}$, FOV was 25.6 , matrix $256 \times 256$, TR $8.3 \mathrm{msec}$, echo train 3.1, and bandwidth $31.25 \mathrm{kHz}$. A T2-weighted sequence was acquired using a 3D magnetization-prepared cube fast spin gradient echo, FOV 25.6, thickness $1 \mathrm{~mm}$, TR 2500 msec, echo train 100 , bandwidth $62.5 \mathrm{kHz}$, matrix size $256 \times 256$.

\section{Analysis of Activation Volumes and Tractography Modeling of DBS Tissue Activation Contact Volumes}

Volumes of tissue activated around the active contacts were generated with the software SureTune (Medtronic, Inc.) (Table 2), according to their voltage and impedance. ${ }^{3}$ A deterministic method was used for fiber tracking (0.5$\mathrm{mm}$ step lengths, 5000 streamline samples, curvature thresholds $=0.2$ ).

\section{Statistical Analysis}

Statistical comparisons between the preoperative and the postoperative subscores were performed using the paired t-test and the Statistical Package for the Social Sciences software (version 15.0; SPSS, Inc.). The significance threshold was set at $\mathrm{p}=0.05$.

\section{Results}

Our series consisted of 7 consecutive patients with pathological aggressiveness (5 male and 2 female pa- 
tients). Their mean age ( \pm SD) at surgery was 31.4 years ( \pm 13 , range 17-51 years) and the mean follow-up period was 144 months ( \pm 33 , range 6-178 months).

Patients' devices were programmed during the first 1-5 postsurgical days, so the existence of an insertional effect was not evaluated. The initial parameters were $15 \mathrm{~Hz}$ and $450 \mu \mathrm{sec}$, because the first patient experienced an increase in heart rate and blood pressure with higher frequencies. However, a gradual increase in frequency was tolerated during the follow-up as we tried to explore for further improvement, but no changes in the clinical benefit or side effects were observed. During the first years of follow-up the stimulating contacts remained unchanged, except in the last case, in which the patient had not improved with the stimulation.

The patient in case 4 died of paralytic ileus after an orthopedic surgery, 2 years and 10 months after the DBS implantation. He was the patient with OCD, and he had not benefited from the stimulation, nor had he noticed any side effect. He was lost to follow-up 2 years after the surgery. The patient in case 5 died due to a stroke 6 months after the DBS procedure. The patient's family had reported a progressive reduction in her violent attacks and a more regular sleep pattern in the 6 months before her death. The patient in case 3 significantly improved with stimulation, but 6 years after his operation his family requested that the follow-up be performed in a neurosurgical center close to his family's residence, and he was lost to follow-up. We recently telephoned his family and found out that his battery had been replaced in that center 6 months after his referral; a few days later his system got infected and eventually was removed. According to his family, his violent outbursts relapsed after the removal of his system and his medication was increased, which was followed by a side effect that severely affected his general condition, which makes him not eligible for further operations.

The behavior of the patients in cases 1,2, and 6 significantly improved from the first month of stimulation, and their violent attacks became less frequent or disappeared. Their sleep pattern became more regular, and 1 of the 3 epileptic patients had a 30\% reduction in the frequency of his generalized seizures. The last patient derived no improvement from stimulation. Despite changes in frequency, pulse width, and amplitude that were exhaustively tried, these adjustments were not followed by significant clinical effects. Two years after the implantation of the electrodes he experienced an acute episode of decreased consciousness. Stimulation was stopped, without noticing any improvement. After a few weeks the patient's condition improved, but stimulation was not restored. He was diagnosed with a medication overdose.

The ICAP subscores supported these observations, showing a statistically significant reduction in the patients' aggressiveness subscores from the preoperative baseline to the last follow-up (general aggressiveness -47 and -29 , respectively; $p=0.03$ ) (Fig. 1), except for the asocial behavior subscores. After visualizing the MRI with DTI of the 2 patients, the second patient's active contacts were switched to the most distal position, with a further improvement in behavior.

The mother of the patient in case 1 reported that his previous cluster headaches were more frequent since stimulation had been started, but this effect subsided within the first months of stimulation and could be controlled with medication. As we mentioned before, he experienced an increase in his blood pressure and heart rate when stimulation was initially set at high frequencies, so the setting was switched to $15 \mathrm{~Hz}$ and then gradually increased during the first years of follow-up, with good tolerance. The last patient needed a surgical revision of his stimulation system 1 month after the implantation of the electrodes. His extension cable was found to be dysfunctional and was replaced. No other side effects were observed. Four months after the surgery, an increase in the T4 (thyroxine) level, within the high range of normality, was noticed in the patient in case 6 . She remained asymptomatic, and no further action was needed.

\section{Tractography}

The first tractography study shows the patient's previous brain lesions in relation to radiofrequency surgeries. The streamlines from the DBS volumes of tissue activated are shown in Figs. 2 and 3, and in Video 1.

VIDEO 1. Case 1. 3D reconstruction of the patient's DTI sequence on a T1-weighted brain MRI study. The sphere in red shows the volume of tissue activated corresponding to the active contacts; streamlines in yellow are originating from the right electrode, and run medially and toward the VTa, MFB, and DLF. From the left electrode, green streamlines pass through the VTa and then inferiorly involving the MFB and DLF, medial lemniscus, and superior cerebellar peduncle. Copyright Cristina V. Torres. Published with permission. Click here to view.

These streamlines traverse the hypothalamus anteriorly toward the thalamus and anterior internal capsule. Posteriorly, they run caudally through the ventral tegmental area (VTa), reticular formation, medial longitudinal fasciculus, medial lemniscus, medial forebrain bundle (MFB), and dorsal longitudinal fasciculus (DLF). On the left side, some fibers of the superior cerebellar peduncle are involved. From the right electrode, the streamlines from the volumes of tissue activated run medially and toward the VTa, MFB, and DLF. From the left volumes of tissue activated, streamlines traverse toward the VTa, and then inferiorly through the pons and upper medulla in a dorsal and ventral position, involving the main branch of the MFB and DLF, medial lemniscus, and superior cerebellar peduncle (Video 1).

In the second tractography study, electrodes are asymmetrical. We did not obtain fibers involved in the left volumes of tissue activated, which was situated in the medial posterior hypothalamus. From the right electrode, streamlines traverse the hypothalamus anteriorly and then run to the frontal basal cortex through the internal capsule. Posteriorly, they travel through the VTa, the pons, and the upper medulla in a posterior position, involving the main branch of the MFB and DLF, and the medial lemniscus. There are some fibers that run laterally toward the superior part of the left hippocampus through the stria terminalis.

\section{Discussion}

In our series of 7 patients with severe aggressiveness, DBS of the PMH area yielded satisfactory results in 5 cas- 


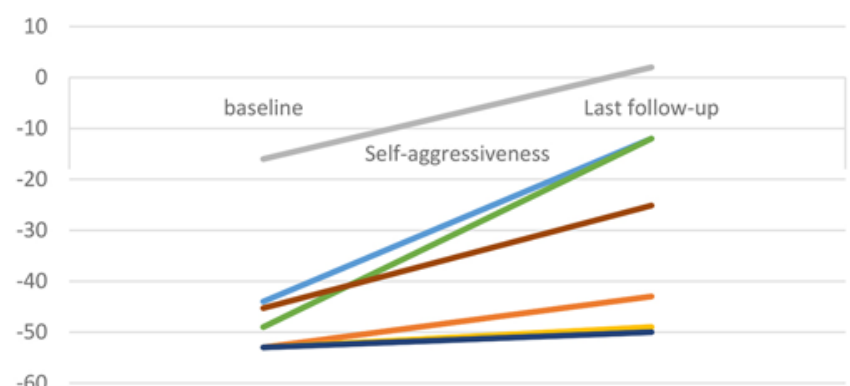

A Patient 1 Patient $2 \longrightarrow$ Patient $3 \longrightarrow$ Patient 4

A

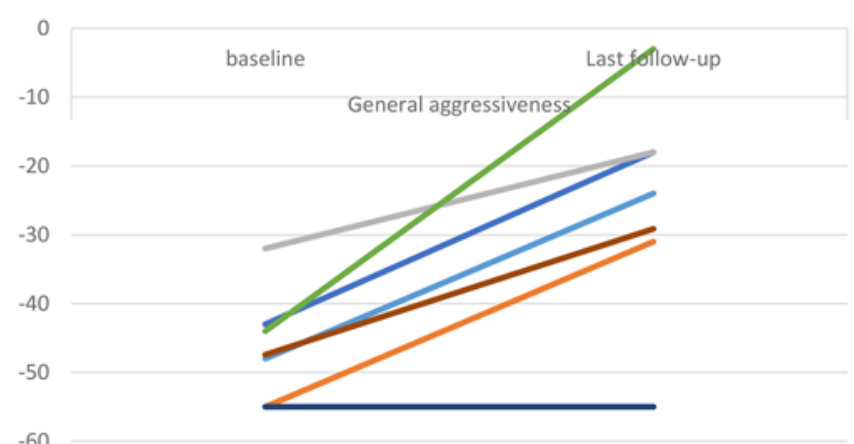

$-60$

C

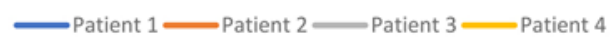

- Patient 5 Patient 6 - Patient 7 - mean

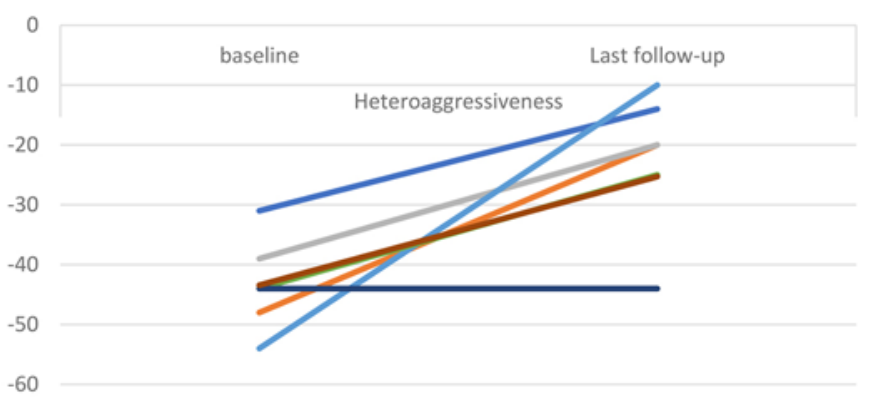

$-60$
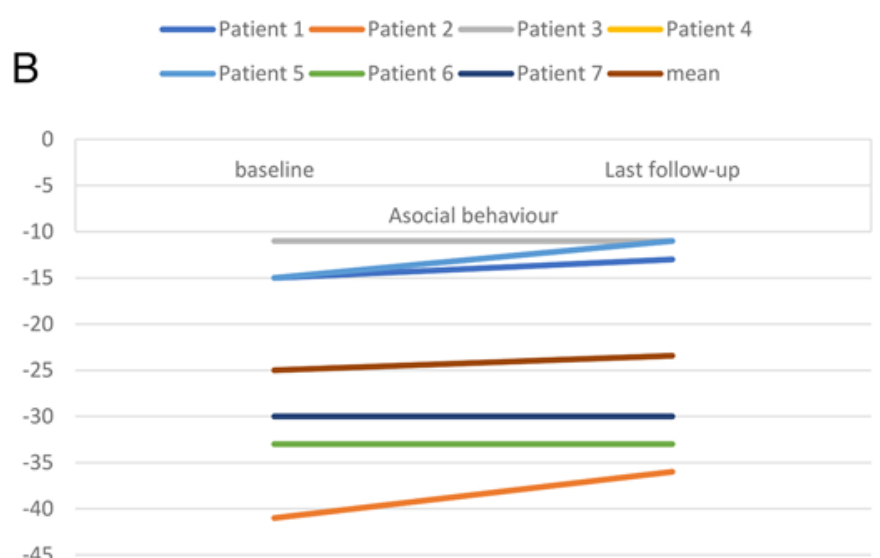

D

FIG. 1. Graphs showing postoperative changes in the scores for self-aggression (upper left); outward aggression (heteroaggressiveness) (upper right); asocial behavior (lower right); and general aggression (lower left). Two of the curves overlap in each panel. Figure is available in color online only.

es. Their violent outbursts were progressively reduced to the point that patients were able to return to live with their family members. No serious complications were observed.

Previous series reporting DBS of the PMH for pathological aggressiveness have hypothesized that its therapeutic effect might be exerted through the hypothalamic connections with hippocampus, cingulum, and amygdala, which are associated with motivation, emotions, and autonomic and endocrine function. ${ }^{6,31}$ The sympathetic effect was also attributed to the hypothalamic connections with the fibers of the DLF (also called the Schütz bundle). ${ }^{18,31,38}$ However, the exact target site varied among the different groups, and connections from the activated contacts to those structures have never been confirmed. ${ }^{9}$ Franzini et al. and BenedettiIsaac et al.'s groups used $\mathrm{x}=2 \mathrm{~mm}, \mathrm{y}=3 \mathrm{~mm}$ posterior, and $\mathrm{z}=5 \mathrm{~mm}$ inferior to the MCP, although for Franzini's group the final position of the electrodes was $3 \mathrm{~mm}$ lateral, $3.5 \mathrm{~mm}$ posterior, and $3.3 \mathrm{~mm}$ below the MCP. ${ }^{12,18,31}$ The trajectory passed through the brain at $60^{\circ}$ in the sagittal angle from the anterior commissure-posterior commissure line and at a $10^{\circ}$ vertical angle in the coronal projection. Micieli et al.'s group, however, switched their " $y$ " coordinate to $1 \mathrm{~mm}$ behind the MCP. Our group used a more anterior and ventral target: $2 \mathrm{~mm}$ lateral to the wall of the third ventricle, $0 \mathrm{~mm}$ in the anterior-posterior direction, and $2 \mathrm{~mm}$ below the intercommissural midpoint. ${ }^{41}$

To our knowledge, this is the first tractographic assess- ment of the volumes of activated brain tissue in responders to this therapy. In our 2 analyzed DTI sequences, the average activation volume involves the PMH, VTa, DLF, and the main trunk of the MFB, which is consistent with the main afferent and efferent posteromedial hypothalamic connections described ${ }^{29}$ (Fig. 4).

Accumulating evidence shows that VTa neurons respond to reward and aversive stimuli. When a reward or signs that predict reward are presented, VTa neurons show an increase in their frequency rate, which decreases if the reward is ultimately not presented. These neurons also temporarily decrease their frequency in response to signals that anticipate adverse stimuli, and have been shown to be involved in the processing of stressful events. ${ }^{10,20,25}$ Recent optogenetic studies also suggest that VTa activation is related to reward processing. Because VTa neurons seem to be involved in regulating different aspects of behavior, direct or indirect neuromodulation of this area by DBS, and the resulting regulation of the secretion of dopamine and other neurotransmitters, might be of great importance in controlling pathological aggression. ${ }^{25}$

The MFB is becoming increasingly important in DBS treatment for psychiatric diseases such as depression and $O C D$, because it has been associated with the processing of rewards and motivation..$^{9,12,35}$ So far it has only been used as a DBS target in open-label case series, with no more than 15 reported cases to date; however, results from those 


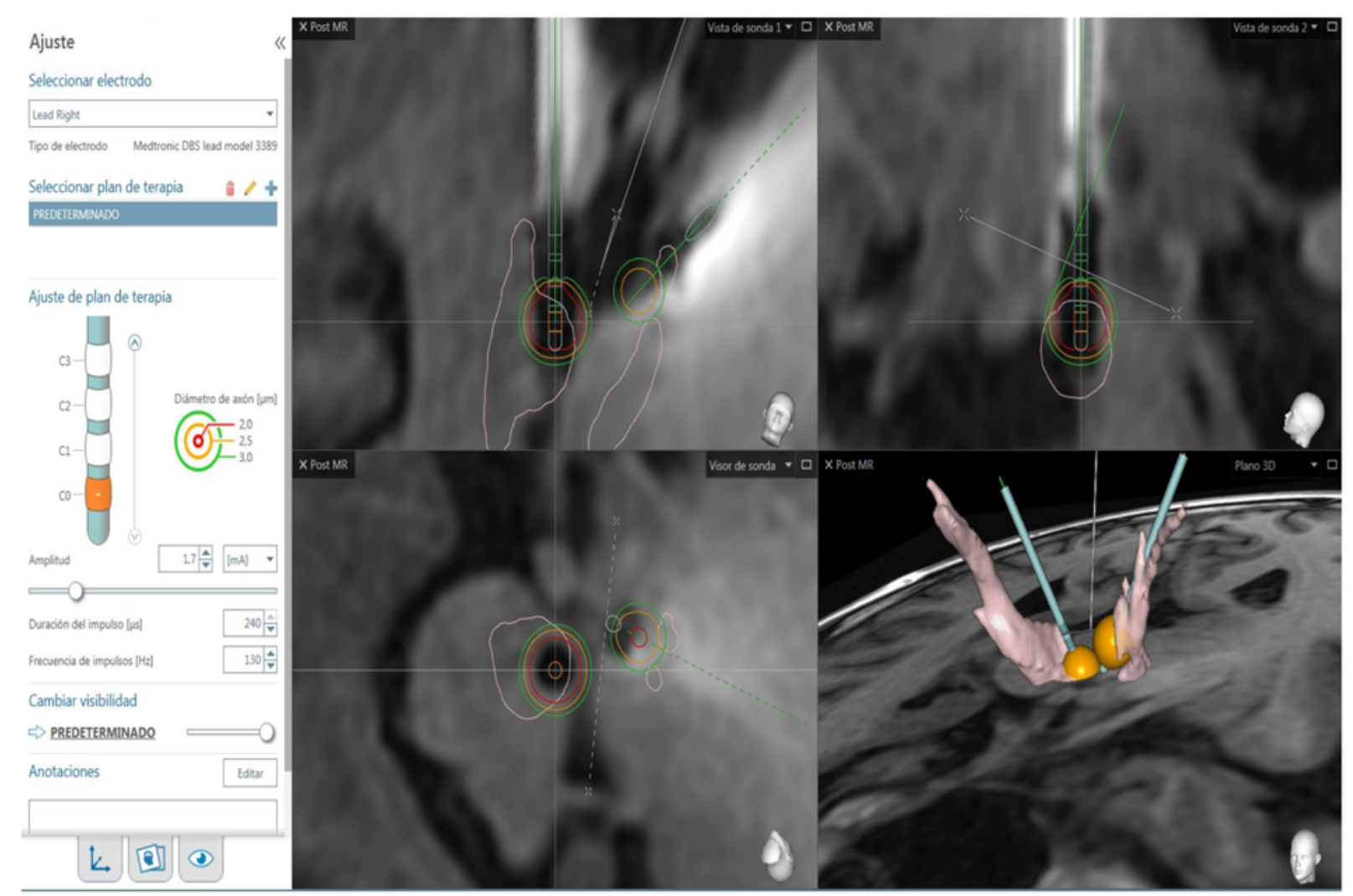

FIG. 2. Images showing the generation of volumes of tissue activated around active DBS contacts with the software SureTune (Medtronic, Inc.). Figure is available in color online only.

studies seem to be encouraging for those disorders. ${ }^{7,8,22}$ Neuromodulation by DBS of this tract might be important as well in controlling aggression.

The last structure that might be mediating the mechanism of action of DBS of the PMH is the DLF, as shown in our analysis. ${ }^{4}$ The DLF is a white matter fiber tract located in the posterior aspect of the brainstem tegmentum. It travels through the periaqueductal gray matter, and it is composed of visceral sensorial ascending fibers and descending axons from the hypothalamus. Ascending tracts originate from nuclei situated in the reticular formation, form synapses in the hypothalamus, and transmit visceral information to the brain. The DLF afferents to the brainstem come from the parabrachial area and carry gustative and general visceral information to the hypothalamus from the solitary tract of the medulla. DLF therefore plays a crucial role in the autonomic manifestations of aggression and might be responsible for the sympathetic adverse effects seen in the patient in case 1 from stimulation. ${ }^{4}$

We did not obtain tractography studies from the left electrode of the patient in case 2, which might lead to the conclusion that unilateral stimulation could be enough for achieving a clinical response. However, the existence of short fibers or inability of the tractographic analysis to detect branching from merging or kissing axons cannot be ruled out. It is also worthwhile to mention that connections with amygdala and hippocampus were only found in the right electrode of the patient in case 2, which might be compared with the first patient's previous lesions (case 1).
To our knowledge, the only studies describing connections from a hypothalamic DBS target to distant structures focused on DBS for cluster headache. ${ }^{28}$ Owen and coworkers used the location of the DBS electrodes as a seed point for tractography in healthy controls. Pathways from the PMH showed tracts through the medial lemniscus, superior cerebellar peduncle, and cerebellum, although their target area was more posterior that ours: $\mathrm{x}=2, \mathrm{y}=-6$, $\mathrm{z}=-8$. Akram et al., using voxel-based morphometry regression analysis, demonstrated that the higher-efficacy predictive cluster's coordinates were lateral and superior ( $\mathrm{x}=6 \mathrm{~mm}, \mathrm{y}=-2 \mathrm{~mm}$, and $\mathrm{z}=-1 \mathrm{~mm}$ to the MCP). Stimulation at that site induced activation in the ipsilateral trigeminal nucleus and ganglion, thalamus, anterior cingulate cortex, somatosensory cortex, and precuneus, and in tracts through the reticular formation and the orbitofrontal regions. Despite the fact that the targets were in the PMH, they are distant from those used for aggression, so it is possible that those different connections might be more implicated in pain control. ${ }^{1,19,24}$

\section{Conclusions}

In our series, 5 of 7 patients with medication-resistant pathological aggressiveness treated with bilateral PMH DBS showed a significant long-term improvement. The PMH, VTa, DLF, and MFB seem to be in the stimulation field and might be responsible for its therapeutic effect. To our knowledge, this is the first report describing the trac- 

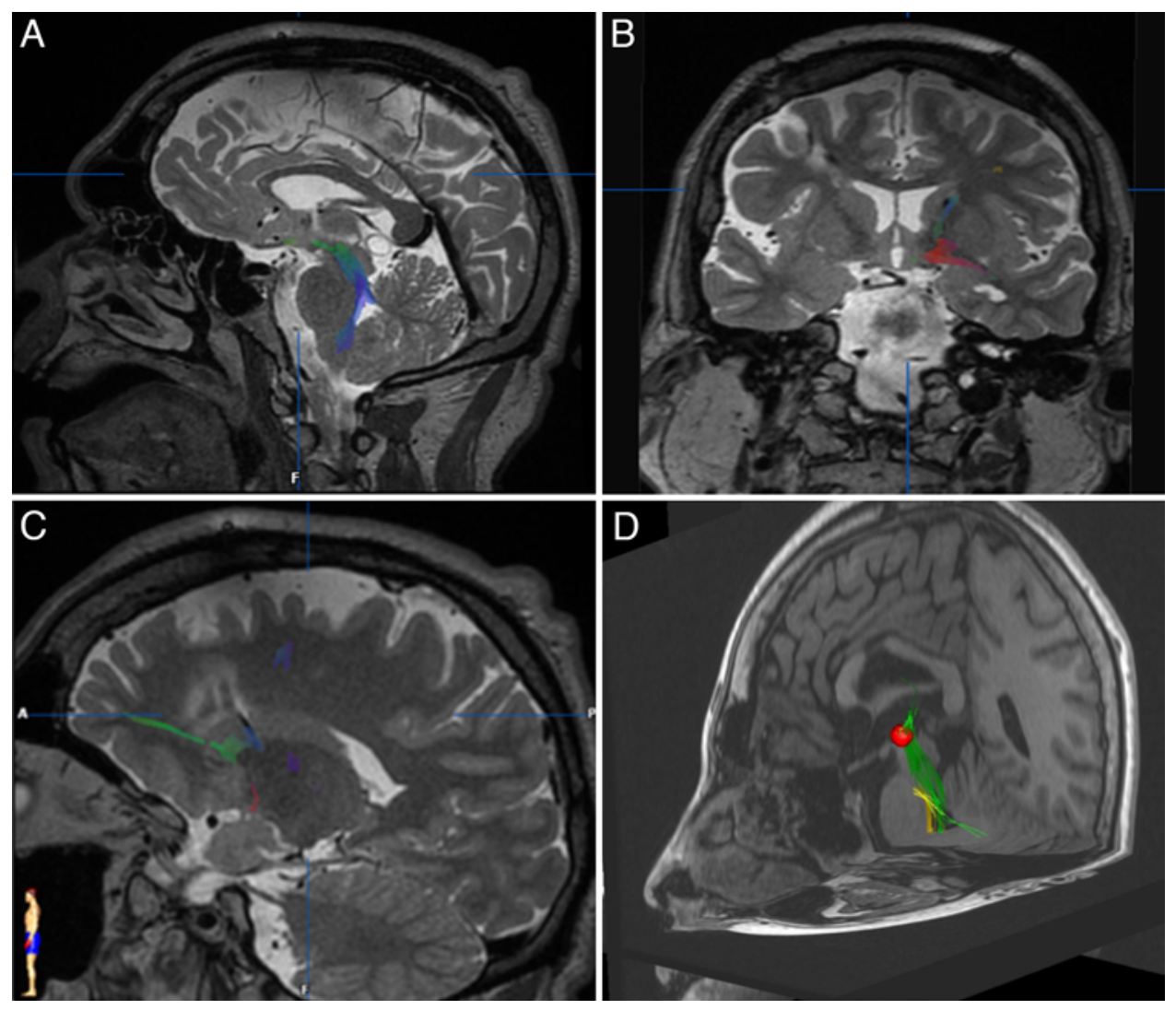

FIG. 3. Tractographic analysis of 2 of the patients treated with DBS of the PMH for aggressiveness. The electrodes are situated inside the MFB and their tips touch the VTa. A-C: Case 2. Images showing streamlines from the volume of tissue activated corresponding to the right electrode, on sagittal and coronal slices, T2-weighted MRI. D: Case 1. 3D reconstruction of the DTI sequence on a T1-weighted brain MRI sequence. Figure is available in color online only.

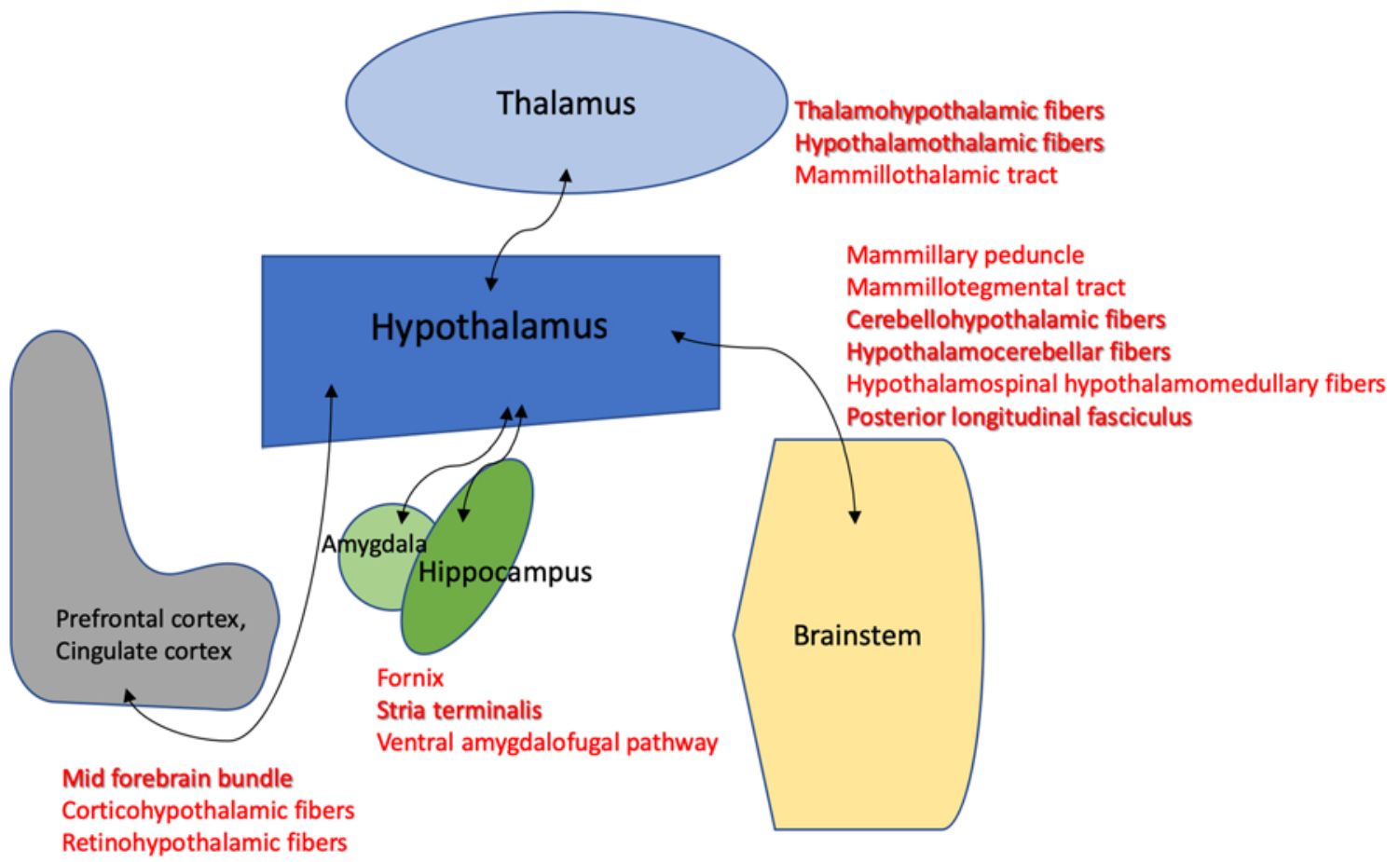

FIG. 4. Schematic representation of the main brain structures involved in aggressiveness control and the connections between them. The tracts that have been delineated from the active contacts of our 2 illustrative patients with aggressiveness (cases 1 and 2) who underwent DBS have been highlighted in bold letters. Figure is available in color online only. 
tography analysis of PMH DBS for aggression. We believe that a more detailed study of the tractographic characteristics of future patients will help with the selection of optimal targets for stimulation.

\section{Acknowledgments}

This study was partially financed by the Ministry of Health FIS PI17/02193 and was partially supported by the Regional European Funds of Development.

\section{References}

1. Akram H, Miller S, Lagrata S, Hyam J, Jahanshahi M, Hariz $\mathrm{M}$, et al: Ventral tegmental area deep brain stimulation for refractory chronic cluster headache. Neurology 86:1676-1682, 2016

2. Andersen R: Cognitive changes after amygdalotomy. Neuropsychologia 16:439-451, 1978

3. Astrom M, Diczfalusy E, Martens H, Wardell K: Relationship between neural activation and electric field distribution during deep brain stimulation. IEEE Trans Biomed Eng 62:664-672, 2015

4. Azmitia EC, Segal M: An autoradiographic analysis of the differential ascending projections of the dorsal and median raphe nuclei in the rat. J Comp Neurol 179:641-667, 1978

5. Balasubramaniam V, Kanaka TS: Amygdalotomy and hypothalamotomy - a comparative study. Confin Neurol 37:195201, 1975

6. Benedetti-Isaac JC, Torres-Zambrano M, Vargas-Toscano A, Perea-Castro E, Alcalá-Cerra G, Furlanetti LL, et al: Seizure frequency reduction after posteromedial hypothalamus deep brain stimulation in drug-resistant epilepsy associated with intractable aggressive behavior. Epilepsia 56:1152-1161, 2015

7. Coenen VA, Honey CR, Hurwitz T, Rahman AA, McMaster J, Bürgel U, et al: Medial forebrain bundle stimulation as a pathophysiological mechanism for hypomania in subthalamic nucleus deep brain stimulation for Parkinson's disease. Neurosurgery 64:1106-1115, 2009

8. Coenen VA, Panksepp J, Hurwitz TA, Urbach H, Mädler B: Human medial forebrain bundle (MFB) and anterior thalamic radiation (ATR): imaging of two major subcortical pathways and the dynamic balance of opposite affects in understanding depression. J Neuropsychiatry Clin Neurosci 24:223-236, 2012

9. Coenen VA, Schlaepfer TE, Maedler B, Panksepp J: Crossspecies affective functions of the medial forebrain bundleimplications for the treatment of affective pain and depression in humans. Neurosci Biobehav Rev 35:1971-1981, 2011

10. Cohen JY, Haesler S, Vong L, Lowell BB, Uchida N: Neurontype-specific signals for reward and punishment in the ventral tegmental area. Nature 482:85-88, 2012

11. Cordella R, Carella F, Franzini A, Marras C, Villani F, Messina $\mathrm{G}$, et al: Intraoperative microrecordings in the posterior hypothalamus of anaesthetized humans with aggressive behaviour. Neurol Sci 31:183-188, 2010

12. Döbrössy MD, Furlanetti LL, Coenen VA: Electrical stimulation of the medial forebrain bundle in pre-clinical studies of psychiatric disorders. Neurosci Biobehav Rev 49:32-42, 2015

13. Espinoza J, Escobar O, Benedetti J: Functional neurosurgery for impulsive aggression: long term follow up. Stereotact Funct Neurosurg 90 (Suppl 1):94, 2012 (Abstract)

14. Franzini A, Marras C, Ferroli P, Bugiani O, Broggi G: Stimulation of the posterior hypothalamus for medically intractable impulsive and violent behavior. Stereotact Funct Neurosurg 83:63-66, 2005
15. Hall RCW: Global assessment of functioning. A modified scale. Psychosomatics 36:267-275, 1995

16. Hernando V, Pastor J, Pedrosa M, Peña E, Sola RG: Lowfrequency bilateral hypothalamic stimulation for treatment of drug-resistant aggressiveness in a young man with mental retardation. Stereotact Funct Neurosurg 86:219-223, 2008

17. Jiménez F, Soto JE, Velasco F, Andrade P, Bustamante JJ, Gómez P, et al: Bilateral cingulotomy and anterior capsulotomy applied to patients with aggressiveness. Stereotact Funct Neurosurg 90:151-160, 2012

18. Jiménez F, Soto JE, Velasco F, Andrade P, Bustamante JJ, Gómez P, et al: Long-term results of posteromedial hypothalamic deep brain stimulation in resistant epilepsy associated to aggressive behavior. Stereotact Funct Neurosurg 92 (Suppl 2):s106, 2014 (Abstract)

19. Kuhn J, Lenartz D, Mai JK, Huff W, Klosterkoetter J, Sturm $\mathrm{V}$ : Disappearance of self-aggressive behaviour in a braininjuried patient after deep brain stimulation of the hypothalamus: technical case report. Neurosurgery 62:E1182, 2008

20. Lammel S, Lim BK, Ran C, Huang KW, Betley MJ, Tye KM, et al: Input-specific control of reward and aversion in the ventral tegmental area. Nature 491:212-217, 2012

21. Mayanagi Y, Hori T, San K: The posteromedial hypothalamus and pain, behavior, with special reference to endocrinological findings. Appl Neurophysiol 41:223-231, 1978

22. Meola A, Yeh FC, Fellows-Mayle W, Weed J, FernandezMiranda JC: Human connectome-based tractographic atlas of the brainstem connections and surgical approaches. Neurosurgery 79:437-455, 2016

23. Micieli R, Rios ALL, Aguilar RP, Posada LFB, Hutchison WD: Single-unit analysis of the human posterior hypothalamus and red nucleus during deep brain stimulation for aggressivity. J Neurosurg 126:1158-1164, 2017

24. Miller S, Akram H, Lagrata S, Hariz M, Matharu M, Zrinzo L: EHMTI-0279. Deep brain stimulation for refractory chronic cluster headache. J Headache Pain 15 (Suppl 1):C44, 2014 (Abstract)

25. Morales M, Margolis EB: Ventral tegmental area: cellular heterogeneity, connectivity and behaviour. Nat Rev Neurosci 18:73-85, 2017

26. Naftolowitz DF, Donovan S, Frances A: DSM-IV. Implications for drug therapy. CNS Drugs 4:1-7, 1995

27. Narabayashi H, Nagao T, Saito Y, Yoshida M, Nagahata M: Stereotaxic amygdalotomy for behavior disorders. Arch Neurol 9:1-16, 1963

28. Owen SLF, Green AL, Davies P, Stein JF, Aziz TZ, Behrens $\mathrm{T}$, et al: Connectivity of an effective hypothalamic surgical target for cluster headache. J Clin Neurosci 14:955-960, 2007

29. Parent AD, Perkins E: The hypothalamus, in Haines DE, Mihailoff GA (eds): Fundamental Neuroscience for Basic and Clinical Applications, ed 5. Philadelphia: Elsevier, 2017

30. Ramamurthi B: Stereotactic operation in behaviour disorders. Amygdalotomy and hypothalamotomy. Acta Neurochir Suppl (Wien) 44:152-157, 1988

31. Rizzi M, Trezza A, Messina G, De Benedictis A, Franzini A, Marras CE: Exploring the brain through posterior hypothalamus surgery for aggressive behavior. Neurosurg Focus 43(3):E14, 2017

32. Rosa M, Franzini A, Giannicola G, Messina G, Altamura AC, Priori A: Hypothalamic oscillations in human pathological aggressiveness. Biol Psychiatry 72:e33-e35, 2012

33. Sano K, Mayanagi Y: Posteromedial hypothalamotomy in the treatment of violent, aggressive behavior. Act Neurochir Suppl (Wien) 44:145-151, 1988

34. Sano K, Yoshioka M, Ogashiwa M, Ishijima B, Ohye C: Postero-medial hypothalamotomy in the treatment of aggressive behaviors. Confin Neurol 27:164-167, 1966

35. Schlaepfer TE, Bewernick BH, Kayser S, Mädler B, Coenen 
VA: Rapid effects of deep brain stimulation for treatmentresistant major depression. Biol Psychiatry 73:1204-1212, 2013

36. Schvarcz JR, Driollet R, Rios E, Betti O: Stereotactic hypothalamotomy for behaviour disorders. J Neurol Neurosurg Psychiatry 35:356-359, 1972

37. Sramka M, Pogády P, Csoková Z, Pogády J: [Long-term results in patients with stereotaxic surgery for psychopathologic disorders.] Bratisl Lek Listy 93:364-366, 1992 (Slovak)

38. Torres CV, Ezquiaga E, Navas M, García Pallero MA, Sola RG: Long-term results of deep brain stimulation of the subcallosal cingulate for medication-resistant bipolar I depression and rapid cycling bipolar II depression. Biol Psychiatry 81:e33-e34, 2017

39. Torres CV, Manzanares R, Sola RG: Integrating diffusion tensor imaging-based tractography into deep brain stimulation surgery: a review of the literature. Stereotact Funct Neurosurg 92:282-290, 2014

40. Torres CV, Sola RG, Pastor J, Pedrosa M, Navas M, GarcíaNavarrete E, et al: Aggressive behavior. response. J Neurosurg 120:287-288, 2014

41. Torres CV, Sola RG, Pastor J, Pedrosa M, Navas M, GarcíaNavarrete E, et al: Long-term results of posteromedial hypothalamic deep brain stimulation for patients with resistant aggressiveness. J Neurosurg 119:277-287, 2013

42. Wada T, Kayaba T: Dorsomedial thalamotomy (V). Results of psychological examination. Tohoku J Exp Med 54:247-249, 1951

43. Weatherman R, Bruininks RH, Hill B, Woodcock R: Inventory for client and agency planning. Rural Spec Educ Q 6:58-59, 1986

\section{Disclosures}

The authors report no conflict of interest concerning the materials or methods used in this study or the findings specified in this paper.

\section{Author Contributions}

Conception and design: Torres. Acquisition of data: Torres, Blasco, Navas García, Pérez Rodrigo. Analysis and interpretation of data: Torres, Ezquiaga, Manzanares. Drafting the article: Torres, Ezquiaga, Manzanares. Critically revising the article: Blasco, Navas García, Pastor, Vega-Zelaya, Pulido Rivas, Pérez Rodrigo, Manzanares. Reviewed submitted version of manuscript: Blasco, Navas García, Ezquiaga, Pastor, Vega-Zelaya, Pulido Rivas, Pérez Rodrigo, Manzanares. Approved the final version of the manuscript on behalf of all authors: Torres. Statistical analysis: Torres. Administrative/technical/material support: Torres. Study supervision: Manzanares.

\section{Supplemental Information \\ Videos}

Video 1. https://vimeo.com/378773400.

\section{Correspondence}

Cristina V. Torres: University Hospital La Princesa, Madrid, Spain. cristinatorresdiaz@yahoo.es. 